\title{
Saúde e direitos reprodutivos no contexto da pandemia da COVID-19
}

\author{
Naiá Ortelan, ${ }^{1}$ Aline dos Santos Rocha, ${ }^{2}$ Flávia B. Pilecco, ${ }^{3}$ \\ Flávia Jôse Alves, ${ }^{4}$ Maria da Conceição C. de Almeida, ${ }^{5}$ \\ Qeren Hapuk R. F. Fernandes, ${ }^{6}$ Ligia Gabrielli7
}

1 Epidemiologista do Centro de Integração de Dados e Conhecimentos para Saúde (CIDACS) da Fundação Oswaldo Cruz (Fiocruz). Graduada em Nutrição pela Universidade Federal de Ouro Preto (UFOP), mestre e doutora em Ciências (Departamentos de Epidemiologia e Nutrição em Saúde Pública, respectivamente) pela Faculdade de Saúde Pública (FSP) da Universidade de São Paulo (USP).

2 Nutricionista pela Universidade Federal do Recôncavo da Bahia (UFRB), mestra e doutoranda pelo Programa de Pós-Graduação em Alimentos Nutrição e Saúde da Escola de Nutrição da Universidade Federal da Bahia (UFBA) e pesquisadora do Centro de Integração de Dados e Conhecimentos para Saúde (CIDACS) da Fundação Oswaldo Cruz (Fiocruz).

3 Professora do Departamento de Medicina Preventiva e Social da Faculdade de Medicina da Universidade Federal de Minas Gerais (UFMG). Graduada em Biomedicina pela Universidade Federal de Ciências da Saúde de Porto Alegre (UFCSPA), mestre e doutora em Epidemiologia pela Universidade Federal do Rio Grande do Sul (UFRGS).

4 Psicóloga pela Universidade Federal da Bahia (UFBA), mestre e doutoranda pelo Programa de PósGraduação do Instituto de Saúde Coletiva (ISC) da UFBA e pesquisadora do Centro de Integração de Dados e Conhecimentos para Saúde (CIDACS) da Fundação Oswaldo Cruz (Fiocruz).

5 Pesquisadora em Saúde Pública do Instituto Gonçalo Moniz (IGM) da Fundação Oswaldo Cruz (Fiocruz). Graduada em Estatística, mestrado em Saúde Comunitária e doutorado em Saúde Pública, ambos na área de epidemiologia pelo Instituto de Saúde Coletiva (ISC) da Universidade Federal da Bahia (UFBA).

6 Doutoranda pelo Programa de Pós-Graduação em Biotecnologia em Saúde e Medicina Investigativa pelo Instituto Gonçalo Moniz (IGM) da Fundação Oswaldo Cruz (Fiocruz) da Bahia. Graduada em Biotecnologia pelo Instituto Multidisciplinar em Saúde (IMS), Campus Anísio Teixeira (CAT) da Universidade Federal da Bahia (UFBA). Mestrado em Biociências (UFBA/IMS-CAT).

7 Pesquisadora associada do Programa Integrado de Pesquisa em Gênero e Saúde (MUSA) do Instituto de Saúde Coletiva (ISC) da Universidade Federal da Bahia (UFBA). Graduada em Medicina com especialização em Ginecologia e Obstetrícia pela UFBA, mestrado em Saúde Comunitária e doutorado em Saúde Pública, ambos na área de epidemiologia, no ISC da UFBA.

ORTELAN, N.; ROCHA, A. dos S.; PILECCO, F. B.; ALVES, F. J.; ALMEIDA, M. da C. C. de; FERNANDES, Q. H. R. F.; GABRIELLI, L. Saúde e direitos reprodutivos no contexto da pandemia da COVID-19. In: BARRETO, M. L.; PINTO JUNIOR, E. P.; ARAGÃO, E.; BARRAL-NETTO, M. (org.). Construção de conhecimento no curso da pandemia de COVID-19: aspectos biomédicos, clínico-assistenciais, epidemiológicos e sociais. Salvador: Edufba, 2020. v. 2. DOI: https://doi.org/10.9771/9786556300757.024 


\section{Introdução}

A pandemia causada pelo Coronavírus da Síndrome Respiratória Aguda Grave 2 (SARS-CoV-2), o agente causador da COVID-19, impôs de modo único nos últimos 100 anos a necessidade de radicalizar o distanciamento social. Gerou sobrecarga generalizada dos serviços de saúde, principalmente naqueles relacionados à atenção hospitalar e aos cuidados críticos, mas também à atenção primária, fazendo emergir questões referentes aos cuidados com as mulheres em seu momento reprodutivo.

No curto período de tempo desde o início da pandemia, a atribuição de gravidade às gestantes com a COVID-19 variou desde o risco habitual relacionado à idade, até a percepção de que elas têm, não somente uma maior probabilidade de admissão hospitalar ou em Unidades de Tratamento Intensivo (UTI), como também maior risco de morrer da doença, quando comparadas a mulheres não grávidas da mesma faixa etária. Do mesmo modo, a transmissão materno-fetal do SARS-CoV-2 que inicialmente parecia inexistente, mostrou-se, com o evolver da pandemia, como uma possibilidade concreta, ainda que aparentemente não seja o caso da maioria das gestantes. Portanto, mulheres grávidas são hoje consideradas um dos grupos de risco para a COVID-19, tornando-se as 
medidas de prevenção, a identificação precoce dos casos e a conduta clínica ajustada para as peculiaridades do estado gravídico, uma prioridade no planejamento e enfrentamento da crise sanitária.

Os efeitos da pandemia da COVID-19 têm exigido esforços globais para o seu enfrentamento, tendo em vista que as suas graves consequências sociais e econômicas afetam, direta ou indiretamente, a saúde da população. Os novos arranjos na organização dos serviços de saúde, a redefinição de prioridades assistenciais resultantes da crise sanitária e os problemas logísticos na oferta de insumos e medicamentos aprofundam os desafios para a garantia do acesso à saúde sexual e reprodutiva, especialmente para grupos mais vulneráveis.

Neste capítulo, serão abordadas questões relacionadas às restrições na oferta de ações de planejamento familiar, incluindo o aborto legal, bem como os desafios impostos à manutenção da atenção ao pré-natal, parto e puerpério, as evidências científicas sobre gestantes com COVID-19 e os desfechos materno-fetais. Por fim, serão discutidos os cuidados pós-natais, em tempos de pandemia.

Este capítulo é decorrente do relatório Saúde e Direitos Reprodutivos no cenário da COVID $-19,{ }^{8}$ produzido pelo Grupo de Síntese de Evidências sobre as Estratégias de Controle da COVID-19 da Rede CoVida.

8 Ver em: https://redecovida.org/relatorios/

saude-e-direitos-reprodutivos-no-cenario-da-covid-19/ 


\section{Impacto da pandemia na atenção à saúde sexual e à saúde reprodutiva}

Desde o início da pandemia da COVID-19, instituições multilaterais, como o Fundo das Nações Unidas para a População (UNFPA) e a Organização Mundial de Saúde (OMS), têm indicado que a falta da oferta adequada de serviços de Saúde Sexual e Saúde Reprodutiva (SSSR) tem sido um significativo problema de saúde pública durante epidemias e reforçado a importância de sua manutenção. (UNFPA ASIA PACIFIC REGIONAL OFFICE, 2020; WHO, 2020c)

A preocupação dessas instituições se fundamenta na experiência de outras epidemias, como a de Ebola, na África do Oeste, onde se constatou um aumento de cerca de $75 \%$ da mortalidade materna nos países atingidos - de 38\% na Guiné a 111\% na Libéria - e da mortalidade infantil, além da transmissão do vírus por meio do leite materno. (MULLAN, 2015; THORSON et al., 2020) Além disso, foram constatadas restrições temporárias no acesso a serviços de planejamento familiar e, em especial, à contracepção. (BIETSCH; WILLIAMSON; REEVES, 2020) Davis e Bennet (2020) argumentam que, no caso da epidemia de Zika, as lições da crise sanitária provocada pelo Ebola não foram aprendidas. Ao solicitarem às mulheres evitar ou postergar a gravidez, os governos não assumiram sua responsabilidade ante as deficiências estruturais que permitiram a emergência e o avanço da doença para as regiões mais desfavorecidas socialmente. Tampouco consideraram a liberdade e a autonomia reprodutiva das mulheres e os contextos legais vigentes que restringiam esse exercício, bem como as dificuldades de acesso aos serviços de SSSR. (HUSSEIN, 2020) Em tempos de COVID-19, urge, portanto, considerar o aprendizado adquirido em outras epidemias, para que violações aos direitos reprodutivos das mulheres não se repitam. 
Assim, no início da pandemia já se previa um impacto nas cadeias de distribuição de contraceptivos, em especial em função da quarentena adotada em países asiáticos, principais produtores de métodos contraceptivos do mundo. (RILEY et al., 2020) $\mathrm{O}$ fechamento de fronteiras e outras restrições impostas às movimentações, adicionalmente, afetam a distribuição desses insumos. Soma-se a isso a suspensão de atendimentos eletivos de saúde e o desvio de recursos humanos e financeiros para conter a pandemia. (HUSSEIN, 2020) Outros fatores que impactam o acesso aos serviços de SSSR são a diminuição da renda, decorrente da recessão econômica, e o receio de contaminação pelo vírus em transportes públicos ou no próprio serviço de saúde. (AHMED; SONFIELD, 2020; TODD-GHER; SHAH, 2020)

Riley e demais autores (2020) estimaram o impacto da pandemia da COVID-19 sobre a SSSR em países de baixa e média renda, em caso de interrupção desses cuidados essenciais. Segundo os autores, um declínio de $10 \%$ no uso de contraceptivos reversíveis de ação curta e longa corresponderia a um aumento de 48,6 milhões de mulheres com demanda por contracepção não atendida e 15,4 milhões de gravidezes indesejadas adicionais. Além disso, uma redução de $10 \%$ na oferta de abortos seguros, implicaria um adicional de 3,3 milhões de abortos inseguros, resultando em um aumento de mil mortes maternas. (RILEY et al., 2020)

A redução dos serviços já tem sido notada em alguns locais. Até o início de abril de 2020, a International Planned Parenthood Federation (IPPF) declarou que 5.633 clínicas e centros de atendimento de planejamento reprodutivo haviam sido fechados em 64 países por causa da pandemia, correspondendo a $14 \%$ do total de pontos de entrega de anticoncepcionais da IPPF em 2018. Adicionalmente, entre os serviços que permaneceram abertos, houve redução de testes do Vírus da Imunodeficiência Humana (HIV), de assistência contraceptiva, do combate à violência 
de gênero e do acesso ao aborto permitido por lei. Outros locais enfrentaram dificuldades em receber suprimentos devido a problemas logísticos e à escassez de contraceptivos e de medicamentos para o HIV no mercado. (INTERNATIONAL PLANNED PARENTHOOD FEDERATION, 2020) No Brasil, uma pesquisa da Organização Não Governamental (ONG) Artigo 19, em parceria com a revista Az Mina e o Portal Gênero e Número, mostrou que, dos 76 serviços que declararam fazer aborto legal em 2019, apenas 55 estavam em funcionamento durante a pandemia. (SILVA; FERREIRA, 2020)

No intuito de manter a oferta de serviços de SSSR, algumas recomendações têm sido adotadas por organismos multilaterais. A oferta de contracepção, os atendimentos a pessoas vivendo com HIV e os serviços de aborto legal devem ser mantidos e, quando possível, devem ser feitos de forma remota, evitando-se ao máximo o contato interpessoal. (RIDGWAY et al., 2020; TOLU; FEYISSA, 2020) O uso da contracepção de alta eficácia e de longa duração é recomendado e tem sido considerada a possibilidade de dispensação de contraceptivos para um período mais longo de uso. (REDE MÉDICA PELO DIREITO DE DECIDIR, 2020; RILEY et al., 2020) Outros recursos a serem considerados incluem o uso das mídias sociais para dispor informações básicas sobre contracepção (TOWNSEND et al., 2020) e a entrega domiciliar de contraceptivos e outros insumos por equipes de saúde, com vistas a reduzir o fluxo de pessoas nas unidades. O único serviço cuja recomendação tem sido a suspensão é o de fertilização assistida. Nesses serviços, recomenda-se o encerramento de ciclos iniciados com o congelamento de embriões e óvulos. (FEDERAÇÃO BRASILEIRA DAS ASSOCIAÇÕES DE GINECOLOGIA E OBSTETRÍCIA, 2020; TUROCY et al., 2020) No entanto, casos de pacientes oncológicas, com baixa reserva ovariana ou idade avançada devem ser avaliados individualmente, ponderando-se os riscos e os benefícios. 
A adoção dessas medidas pode ser mais complexa em cenários com recursos humanos e financeiros mais restritos ou ainda em países com posições mais conservadoras em relação aos direitos sexuais e reprodutivos. Assim, a pandemia tem sido usada para justificar ataques aos direitos das mulheres. Em países ou territórios conservadores, como alguns estados dos Estados Unidos, na Polônia e na Itália, a crise sanitária tem servido como justificativa para a restrição do acesso aos serviços de aborto legal, seja por intervenções ou tentativas de intervenções legais, seja por restrições financeiras e de pessoal que dificultam a continuidade da oferta desses serviços. (BAYEFSKY; BARTZ; WATSON, 2020; BELLIZZI et al., 2020; CARUANA-FINKEL, 2020; CIOFFI; CIOFFI; RINALDI, 2020; TANNE, 2020) Isso pode ser ainda mais grave em países em desenvolvimento, nos quais o acesso aos serviços de SSSR, especialmente contracepção e aborto, já é restrito. (LIMA, 2019; MADEIRO; DINIZ, 2016) Com isso, as mulheres mais afetadas com as restrições impostas serão as pobres, negras, indígenas e pertencentes a outras minorias étnico-raciais, as migrantes, as jovens, com algum tipo de necessidade especial, aquelas em contextos rurais, das matas e das florestas, mulheres ribeirinhas e as que sofrem violência por parceiro íntimo, cujo acesso aos serviços de SSSR já é normalmente restrito. Devemos garantir, portanto, que a resposta à pandemia não marginalize ainda mais aquelas mulheres mais vulneráveis. (TOWNSEND et al., 2020)

O Ministério da Saúde (MS) brasileiro, em notas técnicas sobre o atendimento à mulher durante a pandemia da COVID-19, reduziu sua posição ao ciclo gravídico puerperal. (BRASIL, 2020c, 2020d, 2020e) No dia $1^{\circ}$ de junho, foi lançada a Nota Técnica $\mathrm{n}^{\circ}$ 16/2020-COSMU/CGCIVI/DAPES/SAPS/MS, que reconheceu como essenciais os serviços de saúde sexual e reprodutiva, dentre eles o de abortamento seguro para os casos previstos em lei. Essa Nota Técnica não propunha nenhuma ação nova, apenas reforçava as já 
previstas na Política de Atenção Integral à Saúde das Mulheres e a continuidade dos serviços já prestados. (BRASIL, 2020f) No entanto, após três dias, ela foi retirada da página do MS (BRASIL, 2020a) e dois funcionários, coordenadores de Saúde da Mulher e de Saúde do Homem, foram exonerados. Ao final de setembro de 2020, às vésperas do julgamento do Supremo Tribunal Federal (STF) sobre a Alegação de Descumprimento de Preceito Fundamental $(\mathrm{ADPF}) \mathrm{n}^{\circ} 442$, que poderia permitir o aborto sob demanda até a $12^{\circ}$ semana de gestação, o MS editou as Portarias $n^{\circ} 2.282$ do MS e $\mathrm{n}^{\circ} 2.561$ do MS, propondo uma série de medidas para dificultar o acesso aos serviços de SSSR, com o objetivo de desestimular a procura por serviços de aborto legal. A Portaria $\mathrm{n}^{\circ} 2.282$ do MS pretendia obrigar os profissionais de saúde a notificar à autoridade policial os casos de estupro, contrariando normas técnicas do próprio MS, bem como informar às pacientes os riscos relacionados ao aborto e oferecer-lhes a possibilidade de visualizar o feto ou embrião por meio de ultrassom. (ABRASCO, 2020) A Portaria $\mathrm{n}^{\circ} 2.561$ do MS, por sua vez, revogou a obrigação de oferecer a visualização do feto proposta na Portaria $\mathrm{n}^{\circ} 2.282$ do MS, mas manteve suas demais proposições. (BRASIL, 2020b)

\section{Gravidez, parto, desfechos materno-fetais, transmissão vertical e atenção pós-natal}

\section{Atenção pré-natal e assistência ao parto}

A manutenção dos cuidados pré-natais de qualidade durante o período da pandemia é recomendada pela OMS (UNA-SUS, 2020), e, para acomodar a demanda de atendimento necessário às gestantes e puérperas com o novo coronavírus, foram necessários rearranjos institucionais. O Fundo das Nações Unidas para a 
Infância (Unicef) sugeriu modos alternativos da assistência pré-natal, com consultas por telefone, quando possível, e presenciais, quando necessário, de modo a proteger a gestante e a equipe de saúde, sempre levando em conta as condições de risco gestacional, avaliadas individualmente.

No Brasil, notas técnicas foram editadas com recomendações para o manejo de gestantes, parturientes e puérperas, nas quais está incluído o atendimento presencial garantido a todas as gestantes assintomáticas. Para as sintomáticas e sem risco gestacional, há a indicação do adiamento da consulta em duas semanas, se possível, ou o atendimento em local reservado. Na Atenção Primária, deve-se monitorar todas as grávidas com síndrome gripal, viabilizando a comunicação e orientação rápida em caso de agravamento dos sintomas (Figura 1). Essas recomendações sugerem ainda, alternativamente, consultas domiciliares ou em locais específicos para gestantes assintomáticas. (UNICEF, 2020b)

A garantia de uma experiência segura e digna de parto foi uma das recomendações da OMS, incluindo o respeito à parturiente e à posição de parto pretendida/escolhida, a presença de acompanhante, comunicação clara da equipe de saúde e estratégias de alívio das dores do parto. (UNA-SUS, 2020)

A indicação do tipo de parto não se modifica em pacientes com a COVID-19. O momento e o modo do parto devem ser individualizados, dependendo principalmente das condições clínicas maternas e fetais. Não há contraindicação para o parto vaginal em mulheres com suspeita ou confirmação da COVID-19. A necessidade da aceleração do parto, por qualquer via, pode se estabelecer quando há sofrimento fetal, trabalho de parto prolongado ou deterioração da condição materna. (LIU, H. et al., 2020)

A transmissão hospitalar da COVID-19 constitui-se em uma ameaça séria e concreta para os serviços de saúde. (WANG, D. et al., 2020) Alguns serviços passaram a oferecer, via website 


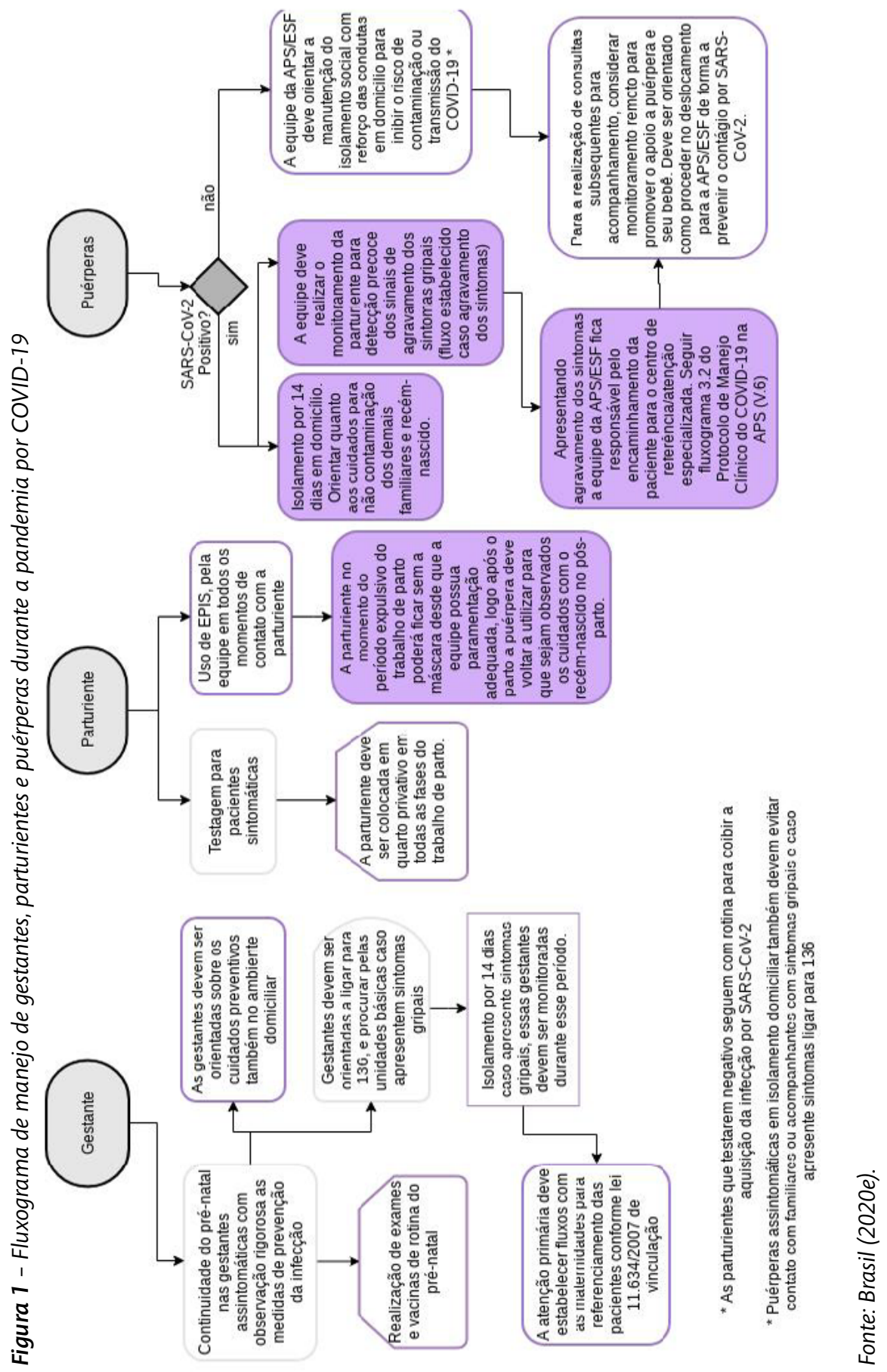


específico, avaliações pré-anestésicas on-line a grávidas para evitar o seu deslocamento aos serviços. Em caso de admissão hospitalar planejada para parto induzido ou cesariana eletiva, é recomendada entrevista telefônica prévia com a gestante e seu acompanhante para identificar a presença de sintomas da COVID-19. (MORAU et al., 2020)

No Brasil, barreiras de acesso aos serviços de atenção à saúde materna, como diferenças regionais da cobertura do pré-natal, acesso aos serviços especializados, peregrinação no momento do parto e deficiências estruturais nas maternidades brasileiras, são observados antes mesmo da pandemia, podendo ter sido intensificadas nesse período. (PACAGNELLA et al., 2012; LEAL et al., 2020) Para as gestantes sintomáticas, o adiamento das consultas e de exames eletivos dificultam a realização do pré-natal adequado. (NAKAMURA-PEREIRA et al., 2020)

O acompanhamento das gestantes com COVID-19 é importante pela alta proporção de internação em UTI, principalmente entre aquelas com idade superior a 35 anos e com presença de comorbidades. (KHALIL et al., 2020) O sobrepeso e, principalmente, a obesidade materna, estão entre as principais comorbidades associadas aos quadros mais graves da COVID-19. (LOKKEN et al., 2020) Além disso, uma alta proporção de desfechos materno-fetais adversos tem sido evidenciada entre as gestantes com COVID-19, como aborto espontâneo, natimortalidade, parto prematuro, cesárea e óbito materno. Essas intercorrências podem ser atribuídas aos efeitos do vírus não só sobre as alterações vasculares fisiológicas da própria gravidez, mas também sobre a função placentária, o desenvolvimento fetal e a imunidade materna. (ZELOP; BONNEY, 2020)

O grande número de partos prematuros associados à COVID-19 precisa ser avaliado com cautela. Gestantes infectadas também manifestaram outras complicações obstétricas, como pré-eclâmpsia, 
contrações irregulares e histórico de natimortalidade, o que pode justificar a indicação de intervenções precoces por comprometimento materno ou fetal, como consequência da piora do quadro respiratório materno. (KNIGHT et al., 2020)

Apesar da infecção por SARS-CoV-2 não ser indicação para aceleração do parto, estudos (CHEN, L. et al., 2020; KNIGHT et al., 2020; LI, N. et al., 2020; LIU, D. et al., 2020; MARASCHINI et al., 2020; PRABHU et al., 2020; QADRI; MARIONA, 2020; SENTILHES et al., 2020) têm evidenciado a realização da cesariana em grávidas com suspeita ou infecção confirmada por COVID-19. Os pesquisadores verificaram que as indicações para o parto cirúrgico incluíram desde complicações na gravidez, até a preocupação com os efeitos ainda pouco compreendidos da COVID-19 sobre a gravidez e o feto. (KNIGHT, M. et al., 2020; MARASCHINI et al., 2020; PRABHU et al., 2020; QADRI; MARIONA, 2020; SENTILHES et al., 2020)

O óbito materno também tem sido observado entre mulheres com COVID-19. (ELLINGTON et al., 2020; KNIGHT et al., 2020; SANTOS et al., 2020; TAKEMOTO et al., 2020) No Brasil, já foram registrados mais de 124 óbitos de gestantes ou puérperas com COVID-19 (TAKEMOTO et al., 2020), sendo encontrada maior proporção de morte materna (17/100 - 17,0\%) em mulheres negras em comparação às brancas (38/423 - 8,9\%). (SANTOS et al., 2020) Considerando a baixa taxa de testagem do país, o número de mortes maternas na população brasileira pode ser ainda maior.

Diante dos dados apresentados, é necessário investigar detalhadamente a relação desses óbitos com a COVID-19, considerando as desigualdades no acesso aos serviços de saúde, frequentes entre as mulheres dos grupos mais vulneráveis da população. Um estudo sueco projetou que, em países de baixa e média renda, a desestruturação dos sistemas de saúde pode levar indiretamente a mais de 12 mil mortes maternas adicionais em decorrência da pandemia 
por COVID-19, em um período de seis meses, sendo essa realidade ainda pior em cenários mais graves. (ROBERTON et al., 2020)

Atenção especial ao pré-natal e parto, especialmente durante pandemias como a da COVID-19, é fundamental para a redução de desfechos materno-fetais adversos. Além disso, a integração do pré-natal com os demais serviços da rede de atenção à saúde com garantia de leitos de internação é essencial para a assistência oportuna às gestantes que apresentam riscos aumentados de desfechos negativos.

\section{Possibilidade de transmissão materno-fetal do SARS-CoV-2}

Apesar de não completamente conhecida, a possibilidade de transmissão vertical da COVID-19 tem sido fartamente descrita e o conhecimento sobre o assunto vem se acumulando com o evolver da pandemia. Diversas infecções virais emergentes vêm ocorrendo nas últimas décadas e, em muitas delas, tem sido demonstrada a possibilidade de transmissão materno-fetal intrauterina, algumas com resultados desastrosos, tais como HIV, Ebola, Hepatite E e Zika vírus. No entanto, nas epidemias mais recentes causadas por coronavírus (SARS e MERS), apesar da ocorrência do aumento da morbimortalidade obstétrica e perinatal, não foram identificados casos de transmissão materno-fetal. (SCHWARTZ; GRAHAM, 2020)

No início da pandemia por SARS-CoV-2, inúmeros relatos de casos de mulheres grávidas com a COVID-19 que deram à luz recém-nascidos saudáveis levaram à falsa percepção da inexistência da transmissão vertical. Os primeiros estudos realizados em pequenas séries de casos com pesquisas de anticorpos corroboraram essa ideia, pois ainda que imunoglobulinas específicas para o SARS-CoV-2 fossem encontradas no sangue dos neonatos de mães com a COVID-19, nenhum deles apresentava sintomas virais 
ou a presença do vírus. $\mathrm{O}$ achado de recém-nascidos com imunoglobulina M (IgM) específica no sangue do cordão umbilical foi a primeira demonstração de que a transmissão vertical do SARS-CoV-2 poderia ser possível, uma vez que esse tipo de imunoglobulina não atravessa a placenta íntegra e seria uma resposta imune fetal a um antígeno qualquer, no caso, o SARS-CoV-2. Mesmo nesses neonatos com IgM positiva, não se confirmou a presença do vírus quando submetidos ao teste de Reação da Transcriptase Reversa seguida pela Reação em Cadeia da Polimerase (RT-PCR), nem a ocorrência de sintomas relacionados com a COVID-19. (GAO et al., 2020; ZENG, H. et al.,2020)

Estudos posteriores verificaram a presença do vírus pelo RT-PCR em recém-nascidos, em momentos diversos do período neonatal, mas tiveram dificuldade em identificar se a transmissão ocorreu antes, durante ou depois do parto. (KNIGHT et al., 2020; ZENG, L. et al., 2020) A esses estudos, seguiu-se a identificação da presença do RNA viral em um neonato, em material colhido imediatamente após o nascimento. (PATANÈ et al., 2020) Outros pesquisadores encontraram o RNA do SARS-CoV-2 no líquido amniótico e na nasofaringe do recém-nascido de uma mulher que deu à luz em condições críticas, levantando a hipótese de que a transmissão vertical do vírus poderia ser possível em infecções maternas particularmente graves. (ZAMANIYAN et al., 2020) Intercorrências obstétricas como o descolamento prematuro da placenta e outras causas de hemorragia durante a gravidez, assim como danos placentários decorrentes de hipóxia grave em mulheres com COVID-19, podem desempenhar um papel facilitador da transmissão vertical do vírus. (DE BERNARDO et al., 2020)

A possibilidade de patologia placentária induzida pela COVID-19 tem sido frequentemente estudada. Os principais achados histológicos nas placentas têm sido as alterações inflamatórias (PATANÈ et al., 2020) e uma maior proporção de alterações 
vasculares e problemas de perfusão, apontando para um potencial de baixa oxigenação fetal, quando comparadas às placentas de fetos de mulheres não infectadas. (SHANES et al., 2020) O encontro de RNA viral em placentas tem sido frequente (FENIZIA et al., 2020) e a presença de alta carga viral foi demonstrada na placenta de um recém-nascido com quadro clínico grave, filho de mulher infectada por SARS-CoV-2. Neste caso, também foram encontradas alterações inflamatórias e vasculares, além da forte presença do vírus na placenta. (FACCHETTI et al., 2020)

A transmissão materno-fetal de infecções pode acontecer antes, durante ou após o parto. Antes do parto, durante a gravidez, pode ocorrer pelas vias ascendente ou hematogênica, sendo esta última mais comum para a transmissão das infecções virais. Infecções adquiridas durante o parto necessitam da presença do patógeno no trato genital materno e, depois do parto, as infecções podem ser transmitidas por via respiratória ou através do leite materno. (SCHWARTZ et al., 2020)

Diversos mecanismos biológicos têm sido descritos como necessários para viabilizar a transmissão materno-fetal do SARS-CoV-2. $\mathrm{O}$ primeiro deles seria a presença de um número crítico de partículas virais na circulação materna, sendo provável que essa quantidade seja maior, quanto mais severa é a doença. (EGLOFF et al., 2020; JUAN et al., 2020) Essas partículas virais chegam à placenta, cruzam a interface materno-fetal e alcançam os vasos fetais. (SCHWARTZ et al., 2020) Para a integração do vírus nos tecidos humanos, inclusive na placenta, é imprescindível a presença de receptores formados pela Enzima de Conversão da Angiotensina-2 (ECA-2), em conjunto com a Serina Protease Transmembranar 2 (TMPRSS2), cuja presença na placenta parece aumentar com o evoluir da gravidez. (ZHENG; DUAN; JIN., 2020; TAGLAUER et al., 2020) 
No entanto, a transmissão intrauterina do SARS-CoV-2 tem sido rara em todas as regiões onde a pandemia está ocorrendo, o que seria esperado com base nas taxas desse tipo de transmissão descritas em infecções por outros tipos de RNA-vírus respiratórios, incluindo os coronavírus. Aparentemente, isso acontece pela dificuldade de as partículas virais penetrarem a barreira placentária e pela baixa afinidade por células hospedeiras, o que pode ser devido a pouca disponibilidade de células na interface materno-fetal contendo o receptor ECA-2 e as enzimas necessárias para a ligação viral. (SCHWARTZ et al., 2020)

Uma observação interessante e que tem chamado a atenção dos pesquisadores mostra que, apesar das alterações placentárias significativas secundárias à infecção materna, a transmissão do SARS-CoV-2 para o feto é evitada na maioria das gestações, o que sugere a ativação de mecanismos antivirais específicos da placenta na interface materno-fetal. (TAGLAUER et al., 2020) Um exemplo disso é o relato de um caso de aborto espontâneo do segundo trimestre em uma gestante com COVID-19, no qual o vírus foi fartamente encontrado na placenta, mas não no feto. (BAUD et al., 2020)

Os dados disponíveis sobre a transmissão intrauterina do SARS-CoV-2 apontam para a necessidade de estudos controlados e, se possível, de base populacional, para a melhor compreensão dos efeitos da COVID-19 sobre a gravidez e seu produto. Infecções congênitas podem ocorrer em qualquer momento da gravidez e ter impactos diferentes no feto, a depender da fase de desenvolvimento deste. Quando ocorre nos primeiros trimestres da gravidez, pode causar aborto, defeitos anatômicos, morte intrauterina, parto prematuro e distúrbios de desenvolvimento neurológico, dentre outros aspectos. (EGLOFF et al., 2020) No entanto, ainda são desconhecidos os efeitos da infecção por COVID-19 no primeiro ou segundo trimestre da gravidez e, embora seja uma doença predominantemente respiratória, sabe-se que afeta vários 
órgãos e sistemas. Enquanto a possibilidade de efeitos intergeracionais do vírus sobre o cérebro - potencializados pela rota materna (PANTELIS et al., 2020), a exemplo do que ocorreu com a epidemia do Zika vírus no Brasil - não estiver exaustivamente estudada, com o acompanhamento rigoroso de coortes de crianças expostas in utero ao SARS-CoV-2, esse ainda será um tema cercado de expectativas.

\section{Atenção pós-natal no cenário da COVID-19}

Ainda existem lacunas quanto aos efeitos da infecção por SARS-CoV-2 na relação puérpera-neonato que vêm sendo estudados ao longo da pandemia por COVID-19. Diante disso, as recomendações nacionais do MS e internacionais - Centros de Controle e Prevenção de Doenças (CDC) e Federação Internacional de Ginecologia e Obstetrícia (FIGO) - é que as consultas pós-natais de seguimento sejam realizadas mesmo durante a pandemia, pois estas são fundamentais para o acompanhamento da saúde e do pleno desenvolvimento do neonato (vigilância do crescimento e desenvolvimento, orientações à família e incentivo à imunização de rotina no período correto). (BRASIL, 2020d) Preconizam que, de preferência, essas consultas sejam conduzidas remotamente e o atendimento presencial seja reservado a neonatos com sintomas que exijam exame físico. (CDC, 2020a; POON et al., 2020a) $\mathrm{O}$ atendimento pós-natal também é uma oportunidade de aconselhamento e orientações aos pais, inclusive com implementação de medidas contraceptivas.

\section{Evidências sobre o leite materno de mulheres com infecção confirmada por GOVID-19}

A amamentação é reconhecida como a melhor forma de alimentação infantil, devido aos inúmeros benefícios em curto e longo prazos à mãe, ao recém-nascido e à sociedade. (ROLLINS et al., 
2016) Porém, a disseminação global do SARS-CoV-2 levou a preocupações sobre a transmissão da doença da mãe infectada ao filho através do leite materno. Está bem estabelecido que a amamentação reduz o risco de uma miríade de condições infecciosas e não infecciosas em curto e longo prazos. (STUEBE, 2009; WHO, 2017) Isso porque existem inúmeros constituintes vivos no leite humano - imunoglobulinas, fatores antivirais, como a lactoferrina, citocinas e leucócitos - que ajudam a destruir patógenos prejudiciais e impulsionam o sistema imunológico do recém-nascido. (UNICEF, 2020d)

Alguns estudos relataram a presença de RNA do SARS-CoV-2 no leite humano (BUONSENSO et al., 2020; GROSS et al., 2020; KIRTSMAN et al., 2020; TAM et al., 2020), enquanto outros não. (CHEN, H. et al., 2020; CUI et al., 2020; DENG et al., 2020; FAN et al., 2020; LACKEY et al., 2020; PACE et al., 2020) É importante observar que a detecção de RNA viral no leite materno não indica necessariamente a infectividade viral. (CHAMBERS et al., 2020)

É igualmente importante compreender o potencial da imunidade passiva da mãe para filho pela ingestão de leite materno. Apesar do conhecimento de que anticorpos do leite materno são produzidos em resposta à infecção viral (FOUDA et al., 2011; MAZUR et al., 2019; POLLARA et al., 2015; TSUTSUMI et al., 1989), poucos estudos examinaram a presença de anticorpos para SARS-CoV-2 no leite humano. (DONG et al., 2020; FOX et al., 2020; PACE et al., 2020) Pace e demais autores (2020) demonstraram que, semelhante à epidemia pelo SARS-CoV em 2003 (ROBERTSON et al., 2004), o leite de mães infectadas continha anticorpos contra o SARS-CoV-2 e suas concentrações estavam correlacionadas com a capacidade do leite de neutralizar efetivamente a infectividade do SARS-CoV-2. Isso significa que o leite produzido por mães infectadas é uma fonte de IgA e IgG anti-SARS-CoV-2. Porém, mais pesquisas 
são necessárias para determinar a capacidade protetora e a duração desses anticorpos.

Como não existem evidências robustas de transmissão do SARS-CoV-2 pelo leite de mães infectadas (CHEN, H. et al., 2020; FAN et al., 2020; KAM et al., 2020; LI et al., 2020; RASMUSSEN; JAMIESON, 2020; WANG, S. et al., 2020; YANG et al., 2020), algumas instituições nacionais e internacionais ${ }^{9}$ se pronunciaram a favor do início ou manutenção da amamentação, desde que tal decisão seja determinada pela mãe com COVID-19, junto aos familiares e profissionais de saúde, respeitando-se as condições clínicas maternas e o desejo de amamentar. (BRASIL, 2020c; CDC, 2020a, 2020b, 2020c; DAVANZO, 2020b; POON et al., 2020b; UNICEF, 2020a; WHO, 2020b) A Figura 2 apresenta o fluxo de decisão para amamentar no contexto da COVID-19.

Ademais, as evidências epidemiológicas sugerem que os danos da interrupção da amamentação superam desproporcionalmente o risco de transmissão da COVID-19. (SHENKER et al., 2020) É preciso considerar também que o atraso no início da amamentação pode interferir no estabelecimento da lactação (PARKER et al., 2015) e aumentar os riscos de morbimortalidade infantil. (NEOVITA STUDY GROUP, 2016; SMITH et al., 2017)

Por fim, o leite materno não é homogêneo e sua composição muda ao longo do período de lactação, impondo a necessidade em determinar se o risco de transmissão da doença pelo leite muda com o estágio da lactação ou nas diferentes fases da infecção materna e em casos assintomáticos.

9 MS do Brasil, Federação Brasileira das Associações de Ginecologia e Obstetrícia (Febrasgo), FIGO, OMS, Unicef, CDC dos Estados Unidos, International Society of Ultrasound in Obstetrics \& Gynecology (Isuog), Royal College of Obstetricians \& Gynecologists (RCOG) - Londres, Academy of Breastfeeding Medicine (ABM), Union of European Neonatal \& Perinatal Societies (UENPS), Italian National Institute of Health (ISS) e Italian Society on Neonatology (SIN). 

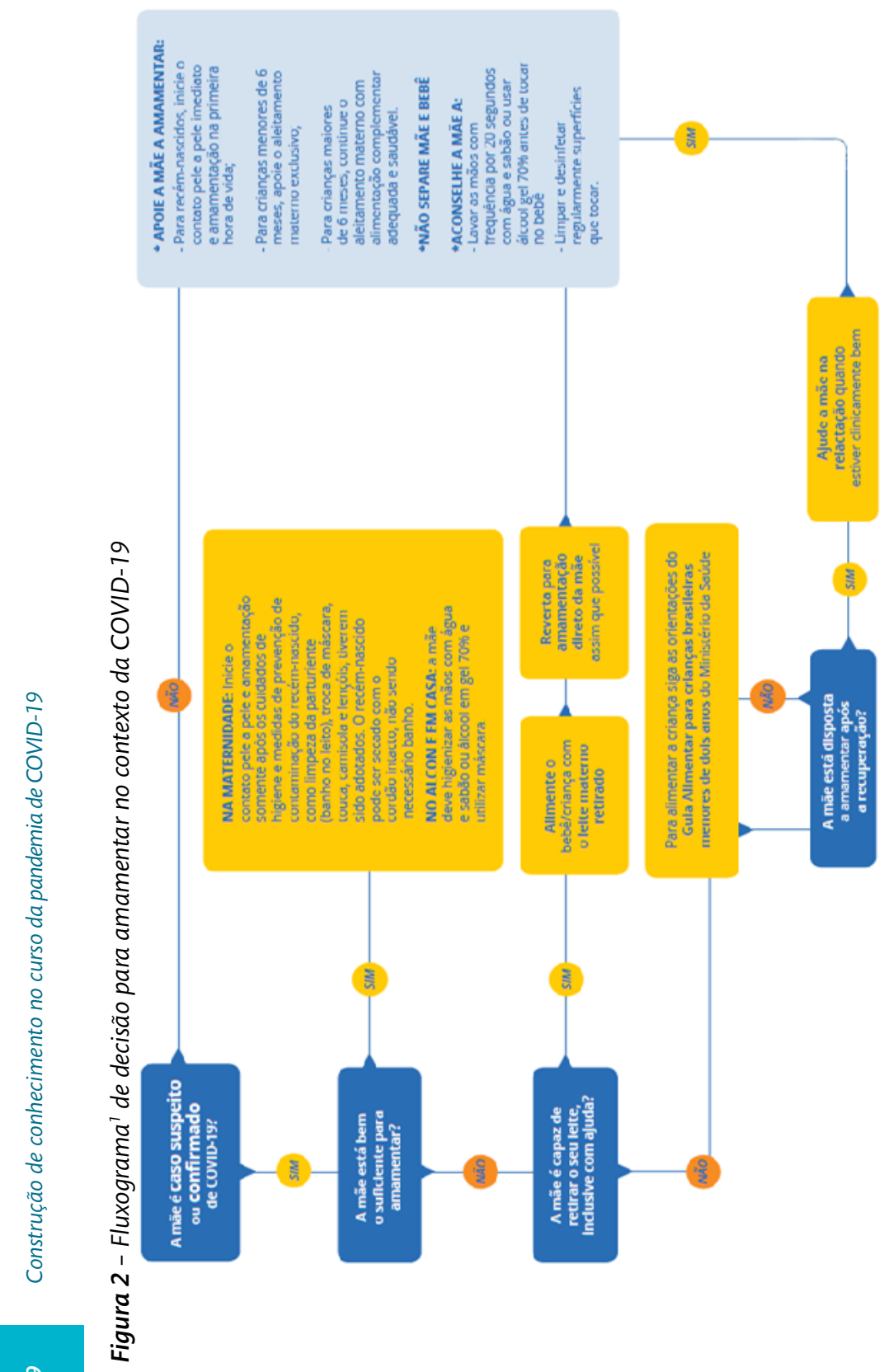


\section{Recomendações a mulheres com GOVID-19 que desejam amamentar}

A possível transmissão do vírus por meio de outros fluidos corporais relacionados indiretamente à amamentação, como suor, gotículas respiratórias ou sangue, não pode ser desconsiderada, devido ao contato próximo da mãe infectada com o neonato ou criança pequena.

Assim, mulheres com infecção suspeita ou confirmada devem adotar algumas precauções, como: lavar as mãos antes de qualquer contato com a criança; proteger a criança de suas secreções respiratórias durante a amamentação; usar máscara durante os cuidados com a criança; descartar as máscaras após o uso ou quando úmidas; higienizar as superfícies com as quais teve contato frequente; suspender visitas e praticar o distanciamento físico de outras pessoas. (BRASIL, 2020c; POON et al., 2020b; UNICEF, 2020d; WHO, 2020c)

As mães precisam se sentir seguras em amamentar seus filhos enquanto estiverem com COVID-19. Caso esteja insegura, com sua saúde debilitada, ou em situação em que outras complicações de saúde a impeçam de cuidar da criança ou de continuar a amamentação direta, mãe e família devem ser incentivadas e apoiadas a retirar o leite materno, manualmente ou com auxílio de bombas extratoras, para oferecê-lo com segurança à criança. (BRASIL, 2020d) A Cartilha para a Mulher Trabalhadora que Amamenta dispõe de orientações para extração do leite. Também é necessário adotar medidas de higiene adequadas, como lavar bem as mãos antes de iniciar o procedimento, usar máscaras cirúrgicas durante a extração e seguir as instruções para limpeza das peças e da bomba após cada uso. (BRASIL, 2020c; CDC, 2020c; POON et al., 2020b) Nos casos em que a mãe estiver bastante sintomática e ainda assim desejar amamentar, deve-se considerar a possibilidade de solicitar assistência para bombear/extrair o leite materno 
- inclusive para continuar estimulando a produção e apojadura do leite - e oferecê-lo à criança usando um copinho, xícara ou colher limpos. (UNICEF, 2020c; WHO, 2020a)

\section{Alojamento conjunto em tempos de GOVID-19}

Em 13 de março de 2020, a OMS publicou orientações sobre o cuidado de recém-nascidos de mulheres com suspeita ou infecção confirmada por COVID-19, recomendando o contato pele a pele imediato pós-parto, assim como a permanência em alojamento conjunto. (WHO, 2020b) Essa recomendação se baseou em evidências de que o estágio grave da doença é raro em neonatos e que o contato pele a pele é importante para a interação precoce mãe-filho, favorecendo o início e manutenção da amamentação e, consequentemente, a saúde infantil. Essa relação também protege contra o desenvolvimento de estresse adicional às mães e aos recém-nascidos. (CARMON, 2020) Nesse caso, algumas medidas devem ser adotadas, como a higienização das mãos e uso de máscaras - cirúrgicas ou N95 - durante contato íntimo com o recém-nascido; suspensão de visitas; acomodação do berço do recém-nascido a pelo menos 1,5 metro da cama da mãe e uso de uma barreira física entre ambos, como um divisor de quarto ou cortina. (DAVANZO, 2020; THE AMERICAN COLLEGE OF OBSTETRICIANS AND GYNECOLOGISTS, 2020)

Contudo, a separação temporária pode ser necessária quando a mãe está muito doente para cuidar do neonato. Tal decisão deve ser individualizada, respeitando o grau de sintomatologia materno e o seu consentimento.

Por outro lado, impor indiscriminadamente uma política de separação do binômio mãe-filho, mesmo que motivada por boas intenções, não leva em conta as evidências epidemiológicas e as sequelas dessa separação. A separação não garante menor exposição viral durante a hospitalização e após a alta, visto que os recém-nascidos podem ser expostos ao vírus por meio de outros 
cuidadores e, se não estiverem recebendo leite materno, a sua proteção contra o SARS-CoV-2 estará reduzida. Após a alta, entrarão em contato com a mãe provavelmente antes que a eliminação viral esteja completa (14 dias), então, a criança, além de exposta ao vírus materno, terá outras fontes de infecção em casa. Por fim, a separação contribui para sobrecarregar os sistemas de saúde e assume que as precauções da OMS - lavar as mãos, usar máscaras, desinfetar superfícies - são insuficientes. Portanto, a separação mãe-filho e a interrupção da amamentação podem expor os neonatos a doenças graves, culminando com óbitos evitáveis em todo o mundo. (DAVANZO, 2020) Os serviços de saúde devem considerar os impactos de curto e longo prazos dessa estratégia em suas políticas.

\section{Saúde mental das puérperas durante a COVID-19}

Durante a gravidez e puerpério, as mulheres estão suscetíveis a desenvolver diversos problemas de saúde mental (NICE, 2014), os quais podem ser agravados durante a pandemia pela COVID-19. Estudos apontam um aumento de sintomas depressivos e ansiedade entre gestantes e puérperas no período pré e pós-parto durante essa pandemia, devido a preocupações com o bem estar do feto/neonato, estabilidade financeira, duração da pandemia e medidas preventivas de higiene e distanciamento social, probabilidade em contrair o vírus, além do próprio isolamento social que pode acentuar os sintomas, inclusive de depressão pós-parto. (CDC, 2020d; CEULEMANS; HOMPES; FOULON, 2020; CHEN, S. et al., 2020; CORBETT et al., 2020; HORSCH et al., 2020; MOYER et al., 2020; WU et al., 2020) A iminência de uma possível separação entre a mãe diagnosticada com SARS-CoV-2 e o neonato também prejudicam sua saúde mental, pelos prejuízos que esta situação pode causar no desenvolvimento do vínculo precoce mãe-filho e no estabelecimento da lactação. 
Diante disso, a FIGO e a OMS recomendam que seja prestada assistência psicológica e, a depender do caso, psiquiátrica, às grávidas e puérperas para acompanhamento e avaliação de sua saúde mental, incluindo o padrão de sono e traços de ansiedade e depressão. (POON et al., 2020a; WHO, 2013, 2016) Assim, ferramentas remotas para suporte psicológico deverão ser adotadas visando mitigar o estresse e gerenciar os distúrbios perinatais da saúde mental durante a pandemia.

\section{Considerações Finais}

Na pandemia da COVID-19, o desafio para os pesquisadores em saúde tem sido fazer ciência em tempo real, dando respostas que saem dos laboratórios para os hospitais e das instituições de pesquisa para os gestores de saúde pública em questão de dias, pois o contrário significaria o acúmulo ainda maior de casos e óbitos pela doença. Nesse contexto, os estudos sobre impactos diretos e indiretos da pandemia sobre a SSSR e, mais especificamente, sobre a saúde da gestante e do feto/neonato têm dado respostas rápidas, mas ainda incompletas e que geram novas perguntas, seguindo o mesmo ritmo do "tempo da ciência que corre para acompanhar o tempo da história”. (ABRASCO, 2020)

O cuidado à saúde sexual e reprodutiva, incluindo o aborto legal, a promoção do planejamento reprodutivo e da contracepção, inclusive de emergência, e os cuidados maternos e neo/pós-natais são essenciais e devem ser definidos como tal por gestores e profissionais de saúde. Assim, a alocação de recursos humanos e materiais necessários para manter tais serviços em pleno funcionamento deve ser garantida mesmo durante a pandemia.

O uso da telessaúde deve ser ampliado, contemplando os cuidados necessários às mulheres de todas as idades e considerando 
os desafios postos, como o acesso desigual à internet. Para as populações mais vulneráveis/marginalizadas, é fundamental que sejam mantidas equipes móveis de saúde que provenham os cuidados de SSSR, atenção pré e pós-natal, aliadas à realização de campanhas publicitárias para informar sobre a disponibilidade desses serviços.

O contexto brasileiro impõe enormes desafios ao cumprimento dessas recomendações. O país apresenta grande e crescente desigualdade social, com um enorme contingente de pessoas vivendo abaixo da linha da pobreza, em situação de grande vulnerabilidade. $\mathrm{O}$ desemprego ascende a níveis alarmantes e tende a se tornar um problema ainda mais grave após a pandemia. Além disso, a Emenda Constitucional $\mathrm{n}^{\circ} 95$ agravou os mecanismos de financiamento do SUS, contribuindo para a desarticulação e desestruturação dos serviços de atenção primária à saúde, dificultando a implementação de medidas que podem mitigar os efeitos dessa pandemia.

\section{Referências}

AHMED, Z:; SONFIELD, A. The COVID-19 Outbreak: Potential Fallout for Sexual and Reproductive Health and Rights. Mar. 2020. Disponível em: https://www. guttmacher.org/article/2020/03/covid-19-outbreak-potential-fallout-sexual-andreproductive-health-and-rights. Acesso em: 18 maio 2020.

Anna E Thorson, Megan Foeller, Pura Rayco-Solon, Zita Weise Prinzo, João Paulo Souza, Juan Pablo Peña-Rosas. Ebola virus disease and breastfeeding. The Lancet, Volume 395, Issue 10223, 15-21 February 2020, Page 468. DOI: https://doi. org/10.1016/S0140-6736(20)30353-6. Link: https://www.thelancet.com/journals/ lancet/article/PIIS0140-6736(20)30353-6/fulltext 
ASSOCIAÇÃO BRASILEIRA DE SAÚDE COLETIVA - ABRASCO. Em defesa dos direitos sexuais e reprodutivos das meninas e mulheres e em repúdio à Portaria No 2282/MS. ago. 2020. Disponível em: https://www.abrasco.org.br/site/noticias/ posicionamentos-oficiais-abrasco/nota-em-defesa-dos-direitos-sexuais-ereprodutivos-das-meninas-e-mulheres-e-em-repudio-a-portaria-n-2282-doministerio-da-saude/51724/. Acesso em: 11 set. 2020.

BAUD, D. et al. Second-Trimester Miscarriage in a Pregnant Woman With SARS-CoV-2 Infection. JAMA, Chicago, v. 323, n. 21, p. 2198-2200, 2020.

Disponível em: https://jamanetwork.com/journals/jama/fullarticle/2765616. Acesso em: 18 maio 2020.

BAYEFSKY, M. J.; BARTZ, D.; WATSON, K. L. Abortion during the Covid-19 Pandemic - Ensuring Access to an Essential Health Service. New England Journal of Medicine, Boston, v. 382, n. 19, p. e47, May 2020.

BELLIZZI, S. et al. Safe abortion amid the COVID-19 pandemic: The case of Italy. International Journal of Gynecology \& Obstetrics, New York, v. 150, n. 2, p s 254-255, May 2020.

BIETSCH, K.; WILLIAMSON, J.; REEVES, M. Family Planning During and After the West African Ebola Crisis. Studies in Family Planning, Malden, MA, v. 51, n. 1, p. 71-86, Mar. 2020.

BRASIL. Ministério da Saúde. Ministério da Saúde esclarece nota técnica. Brasília, DF, abr. 2020a. Disponível em: https://www.gov.br/saude/pt-br/assuntos/noticias/ ministerio-da-saude-esclarece-nota-tecnica. Acesso em: 6 jun. 2020.

BRASIL. Ministério da Saúde. Portaria $n^{\circ} 2.561$, de 23 de setembro de 2020. Dispõe sobre o Procedimento de Justificação e Autorização da Interrupção da Gravidez nos casos previstos em lei, no âmbito do Sistema Único de Saúde-SUS. Diário Oficial da União: seção 1, n. 184, p. 89, Brasília, DF, n. 184, 24 set. 2020b.

BRASIL. Ministério da Saúde. Secretaria de Atenção Primária à Saúde. Nota Técnica $n^{\circ}$ 9/2020-COSMU/CGCIVI/DAPES/SAPS/MS - Recomendações para o trabalho de parto, parto e puerpério durante a pandemia da COVID-19. Brasília, DF, 2020c. Disponível em: https://egestorab.saude.gov.br/image/?file=20200415_N_ notatecnica92020COSMUCGCIVIDAPESSAPSMS_8781753489806424666.pdf. Acesso em: 29 out. 2020. 
BRASIL. Ministério da Saúde. Secretaria de Atenção Primária à Saúde. Nota Técnica n 10/2020-COSMU/CGCIVI/DAPES/SAPS/MS. Brasília, DF, 2020d. Disponível em: https://egestorab.saude.gov.br/image/?file=20200415_N_ notatecnica102020COSMUCGCIVIDAPESSAPSMS_1287575329029070378.pdf. Acesso em: 29 out. 2020.

BRASIL. Ministério da Saúde. Secretaria de Atenção Primária à Saúde. Nota Técnica n 12/2020-COSMU/CGCIVI/DAPES/SAPS/MS - infecção COVID-19 e os riscos às mulheres no ciclo gravidico puerperal. Brasília, DF, 2020e. Disponível em: http://189.28.128.100/dab/docs/portaldab/documentos/NT_N_12_2020_COSMU_ CGCIVI_DAPES_SAPS_MS.pdf. Acesso em: 29 out. 2020.

BRASIL. Ministério da Saúde. Secretaria de Atenção Primária à Saúde. Nota Técnica n 16/2020-COSMU/CGCIVI/DAPES/SAPS/MS. Brasília, DF, jun. $2020 f$.

BRASIL. Ministério da Saúde. Fluxo de decisão para amamentação no contexto da COVID-19. Brasília, DF, 2020g. Disponível em: https://egestorab.saude.gov.br/ image/?file=20200805_N_fluxocovidamamentacaofinal_1685233604290680323. pdf. Acesso em: 29 out. 2020.

BUONSENSO, D. et al. Neonatal Late Onset Infection with Severe Acute Respiratory Syndrome Coronavirus 2. American Journal of Perinatology, New York, v. 37, n. 8 , p. 869-872, 2020.

CARMON, I. Coronavirus and Newborns: 'They Separated Me From My Baby'. The Cut, New York, 7 Apr. 2020. Disponivel em: https://www.thecut.com/2020/04/ coronavirus-newborns-hospitals-parents.html. Acesso em: 30 out. 2020.

CARUANA-FINKEL, L. Abortion in the time of COVID-19: Perspectives from Malta. Sexual and Reproductive Health Matters, [s. I.], v. 28, n. 1, p. 1-4, June 2020.

CENTERS FOR DISEASE CONTROL AND PREVENTION - CDC. Pregnancy, Breastfeeding, and Caring for Newborns. Atlanta, 2020a. Disponível em: https:// www.cdc.gov/coronavirus/2019-ncov/need-extra-precautions/pregnancybreastfeeding.html. Acesso em: 28 out. 2020.

CENTERS FOR DISEASE CONTROL AND PREVENTION - CDC. Considerations for Inpatient Obstetric Healthcare Settings. Atlanta, 2020b. Disponível em: https://www. cdc.gov/coronavirus/2019-ncov/hcp/inpatient-obstetric-healthcare-guidance.html. Acesso em: 28 out. 2020. 
CENTERS FOR DISEASE CONTROL AND PREVENTION - CDC. Coronavirus Disease (COVID-19) and Breastfeeding. Atlanta, 2020c. Disponível em: https://www.cdc.gov/ breastfeeding/breastfeeding-special-circumstances/maternal-or-infant-illnesses/ covid-19-and-breastfeeding.html. Acesso em: 29 out. 2020.

CENTERS FOR DISEASE CONTROL AND PREVENTION - CDC. Evaluation and Management Considerations for Neonates At Risk for COVID-19. Atlanta, 2020d. Disponível em: https://www.cdc.gov/coronavirus/2019-ncov/hcp/caring-fornewborns.html. Acesso em: 29 out. 2020.

CEULEMANS, M.; HOMPES, T.; FOULON, V. Mental health status of pregnant and breastfeeding women during the COVID-19 pandemic: A call for action. International Journal of Gynecology \& Obstetrics, Malden, v. 151, n. 1, p. $146-147,2020$.

CHAMBERS, C. et al. Evaluation for SARS-CoV-2 in Breast Milk From 18 Infected Women. JAMA, Chicago, v. 324, n. 13, p. 1347-1348, 2020.

CHEN, H. et al. Clinical characteristics and intrauterine vertical transmission potential of COVID-19 infection in nine pregnant women: a retrospective review of medical records. Lancet, London, v. 395, n. 10226, p. 809-815, Mar. 2020.

CHEN, L. et al. Clinical Characteristics of Pregnant Women with Covid-19 in Wuhan, China. New England Journal of Medicine, Boston, 2020. 1533-4406. Disponível em: http://www.nejm.org/doi/10.1056/NEJMc2009226. Acesso em: 18 maio 2020.

CHEN, S. et al. Psychological Investigation on Pregnant Women during the Outbreak of COVID-19. Research Square, Durham, 2020.

CIOFFI, A.; CIOFFI, F.; RINALDI, R. COVID-19 and abortion: The importance of guaranteeing a fundamental right. Sexual and Reproductive Healthcare, [Amsterdam], v. 25, 2020.

CORBETT, G. A. et al. Health anxiety and behavioural changes of pregnant women during the COVID-19 pandemic. European Journal of Obstetrics, Gynecology, and Reproductive Biology, Limerick, v. 249, p. 96-97, 2020.

CUI, Y. et al. A 55-Day-Old Female Infant Infected With 2019 Novel Coronavirus Disease: Presenting With Pneumonia, Liver Injury, and Heart Damage. The Journal of Infectious Diseases, Oxford, v. 221, n. 11, p. 1775-1781, 2020. 
DAVANZO, R. Breast feeding at the time of COVID-19: do not forget expressed mother's milk, please. Archives of Disease in Childhood. Fetal and Neonatal Edition, London, v. 105, n. 4, p. 455, 2020.

DAVIES, S. E.; BENNETT, B. A gendered human rights analysis of Ebola and Zika: locating gender in global health emergencies. International Affairs, Oxford, v. 92, n. 5, p. 1041-1060, Sept. 2016.

DE BERNARDO, G. et al. The clinical course of SARS-CoV-2 positive neonates. Journal of Perinatology, New York, v. 40, p. 1462-1469, 2020.

DENG, G. et al. Characteristics of pregnant patients with COVID-19 and liver injury. Journal of Hepatology, Amsterdam, v. 73, n. 4, p. 989-991, 2020.

DONG, Y. et al. Antibodies in the breast milk of a maternal woman with COVID-19. Emerging Microbes \& Infections, New York, v. 9, n. 1, p. 1467-1469, 2020.

EGLOFF, C. et al. Evidence and possible mechanisms of rare maternal-fetal transmission of SARS-CoV-2. Journal of Clinical Virology, v. 128, p. 104447, 2020. Disponível em: https://linkinghub.elsevier.com/retrieve/pii/S138665322030189X. Acesso em: 14 jul. 2020.

ELLINGTON, S. et al. Characteristics of Women of Reproductive Age with Laboratory-Confirmed SARS-CoV-2 Infection by Pregnancy Status - United States, January 22-June 7, 2020. Morbidity and Mortality Weekly Report, Atlanta, v. 69, n. 25, p. 769-775, 2020 2020. Disponível em: https://www.cdc.gov/mmwr/ volumes/69/wr/mm6925a1.htm. Acesso em: 14 jul. 2020.

FACCHETTI, F. et al. SARS-CoV2 vertical transmission with adverse effects on the newborn revealed through integrated immunohistochemical, electron microscopy and molecular analyses of Placenta. EBioMedicine, Amsterdam, v. 59, p. 102951, 2020.

FAN, C. et al. Perinatal Transmission of 2019 Coronavirus Disease-Associated Severe Acute Respiratory Syndrome Coronavirus 2: Should We Worry? Clinical Infectious Diseases, Chicago, Mar. 2020.

FEDERAÇÃO BRASILEIRA DAS ASSOCIAÇÕES DE GINECOLOGIA E OBSTETRÍCIA. Perguntas e respostas sobre Reprodução Humana. São Paulo, 13 Apr. 2020. Disponível em: https://www.febrasgo.org.br/pt/covid19/item/1004-perguntas-erespostas-sobre-reproducao-humana. Acesso em: 18 maio 2020. 


\section{FENIZIA, C. et al. IN-UTERO MOTHER-TO-CHILD SARS-COV-2}

TRANSMISSION: viral detection and fetal immune response. medRXiv, [s. I.], 2020. Disponível em: https://www.medrxiv.org/content/10.1101/2020.07.09.20149591v1. Acesso em: 1 ago. 2020.

FLAESCHEN, H. A ciência "em tempo real" na Ágora Abrasco. Rio de Janeiro, Abr. 2020. Disponível em: https://www.abrasco.org.br/site/noticias/ saude-da-populacao/a-ciencia-em-tempo-real-na-agora-abrasco/46727/. Acesso em: 1 ago. 2020.

FOUDA, G. G. et al. HIV-specific functional antibody responses in breast milk mirror those in plasma and are primarily mediated by IgG antibodies. Journal of Virology, Washington, v. 85, n. 18, p. 9555-9567, Sept. 2011.

FOX, A. et al. Evidence of a significant secretory-lgA-dominant SARS-CoV-2 immune response in human milk following recovery from COVID-19.

MedRxiv, [s. I.], 2020.

GAO, J. et al. Disappearance of SARS-CoV-2 Antibodies in Infants Born to Women with COVID-19, Wuhan, China. Emerging Infectious Diseases, Atlanta, v. 26, n. 10, p. 2491-2494, Oct. 2020.

GROSS, R. et al. Detection of SARS-CoV-2 in human breastmilk. Lancet, London, v. 395, n. 10239, p. 1757-1758, 2020.

HORSCH, A.; LALOR, J.; DOWNE, S. Moral and mental health challenges faced by maternity staff during the COVID-19 pandemic. Psychological Trauma: Theory, Research, Practice, and Policy, Washington, 2020. Disponível em: https://content. apa.org/fulltext/2020-37315-001.html. Acesso em: 29 out. 2020.

HUSSEIN, J. COVID-19: What implications for sexual and reproductive health and rights globally? Sexual and Reproductive Health Matters, London, v. 28, n. 1, p. 1746065 , Jan. 2020.

INTERNATIONAL PLANNED PARENTHOOD FEDERATION. COVID-19 pandemic cuts access to sexual and reproductive healthcare for women around the world. London, Apr. 2020. Disponível em: https://www.ippf.org/news/covid-19pandemic-cuts-access-sexual-and-reproductive-healthcare-women-around-world. Acesso em: 18 maio 2020. 
JUAN, J. et al. Effects of coronavirus disease 2019 (COVID-19) on maternal, perinatal and neonatal outcomes: a systematic review. Ultrasound in Obstetrics \& Gynecology, Chichester, v. 56, n. 1, p. 15-27, 2020. DOI: https://dx.doi.org/10.1002/ uog.22088. Disponível em: https://obgyn.onlinelibrary.wiley.com/doi/10.1002/ uog.22088. Acesso em: 25 set. 2020.

KAM, K.-Q. et al. A Well Infant With Coronavirus Disease 2019 With High Viral Load. Clinical Infectious Diseases: An Official Publication of the Infectious Diseases Society of America, Chicago, v. 71, n. 15, p. 847-849, 2020.

KNIGHT, M. et al. Characteristics and outcomes of pregnant women admitted to hospital with confirmed SARS-CoV-2 infection in UK: national population based cohort study. BMJ, London, v. 369, June 2020.

KIRTSMAN, M. et al. Probable congenital SARS-CoV-2 infection in a neonate born to a woman with active SARS-CoV-2 infection. Canadian Medical Association Journal, Ottawa, v. 192, n. 24, p. E647-E650, 2020.

KHALIL, A. et al. SARS-CoV-2 infection in pregnancy: A systematic review and meta-analysis of clinical features and pregnancy outcomes. EClinicalMedicine, London, v. 25, p. 100446, 2020. Disponível em: https://linkinghub.elsevier.com/ retrieve/pii/S2589537020301905. Acesso em: 17 jul. 2020.

LACKEY, K. A. et al. SARS-CoV-2 and human milk: what is the evidence? medRxiv, [s. I.], 2020. Disponível em: https://www.ncbi.nlm.nih.gov/pmc/articles/ PMC7217082/ Acesso em: 1 ago. 2020.

LEAL, M. do D. et al. Prenatal care in the Brazilian public health services. Revista de Saúde Pública, São Paulo, v. 54, 2020. Disponível em: http://www.scielo. $\mathrm{br} /$ scielo.php?script=sci_arttext\&pid=S0034-89102020000100206\&nrm=iso. Acesso em: 1 out. 2020.

LI, N. et al. Maternal and neonatal outcomes of pregnant women with COVID-19 pneumonia: a case-control study. Clinical Infectious Diseases, Chicago, v. 71, n. 16, p. 2035-2041, 2020. Disponível em: https://academic.oup.com/cid/advancearticle/doi/10.1093/cid/ciaa352/5813589. Acesso em: 18 maio 2020.

LI, Y. et al. Lack of Vertical Transmission of Severe Acute Respiratory Syndrome Coronavirus 2, China. Emerging Infectious Diseases, Atlanta, v. 26, n. 6, p. 1335-1336, 2020. 
LIMA, J. D. de. Misoprostol em falta no SUS causa prejuízos à saúde da mulher. Rio de Janeiro, abr. 2019. Disponível em: https://www.abrasco.org.br/site/noticias/ saude-da-populacao/misoprostol-em-falta-no-sus-causa-prejuizos-a-saude-damulher/40211/. Acesso em: 26 jun. 2020.

LIU, D. et al. Pregnancy and Perinatal Outcomes of Women With Coronavirus Disease (COVID-19) Pneumonia: A Preliminary Analysis. American Journal of Roentgenology, Leesburg, VA, v. 21, n. 1, p. 127-132, Mar. 2020. Disponível em: https://www.ajronline.org/doi/10.2214/AJR.20.23072. Acesso em: 18 mar. 2020.

LIU, H. et al. Why are pregnant women susceptible to COVID-19? An immunological viewpoint. Journal of Reproductive Immunology, Amsterdam, v. 139, p. 103122, 2020. Disponível em: https://linkinghub.elsevier.com/retrieve/pii/ S0165037820300437. Acesso em: 5 maio 2020.

LIU, Y. et al. Clinical manifestations and outcome of SARS-CoV-2 infection during pregnancy. Journal of Infection, Kent, UK, Mar. 2020. Disponível em: https://linkinghub.elsevier.com/retrieve/pii/S0163445320301092. Acesso em: 18 maio 2020.

LOKKEN, E. M. et al. Clinical characteristics of 46 pregnant women with a severe acute respiratory syndrome coronavirus 2 infection in Washington State. American Journal of Obstetrics and Gynecology, New York, v. 223, n. 6, 2020. Disponível em: https://pubmed.ncbi.nlm.nih.gov/32439389https://www.ncbi.nlm.nih.gov/pmc/ articles/PMC7234933/. Acesso em: 1 ago. 2020.

MADEIRO, A. P.; DINIZ, D. Serviços de aborto legal no Brasil - um estudo nacional. Ciência \& Saúde Coletiva, Rio de Janeiro, v. 21, n. 2, p. 563-572, fev. 2016.

MARASCHINI, A. et al. Coronavirus and birth in Italy: results of a national population-based cohort study. MedRxiv, [s. I.], 2020. Disponível em: https://www. medrxiv.org/content/10.1101/2020.06.11.20128652v1. Acesso em: 1 out. 2020.

MAZUR, N. I. et al. Breast Milk Prefusion F Immunoglobulin G as a Correlate of Protection Against Respiratory Syncytial Virus Acute Respiratory IIIness. The Journal of Infectious Diseases, Oxford, v. 219, n. 1, p. 59-67, 2019.

MORAU, E. et al. Anaesthesia and intensive care in obstetrics during the COVID-19 pandemic. Anaesthesia Critical Care \& Pain Medicine, Issy-les-Moulineaux cedex, FRA, v. 39, n. 3, p. 345-349, 2020. Disponível em: https://linkinghub.elsevier.com/ retrieve/pii/S2352556820300898. Acesso em: 18 maio 2020. 
MOYER, C. A. et al. Pregnancy-related anxiety during COVID-19: a nationwide survey of 2740 pregnant women. Archives of Women's Mental Health, [s. I.], p. 1-9, Sept. 2020.

MULLAN, Z. The cost of Ebola. The Lancet Global Health, [London], v. 3, n. 8 , p. e423, Aug. 2015.

NAKAMURA-PEREIRA, M. et al. COVID-19 and Maternal Death in Brazil: An Invisible Tragedy. Revista Brasileira de Ginecologia e Obstetrícia, Rio de janeiro, v. 42, n. 8, p. 445-447, 2020. Disponível em: http://www.scielo.br/scielo.php?script=sci_ arttext\&pid=S0100-72032020000800445\&nrm=iso. Acesso em: 1 out. 2020.

NATIONAL INSTITUTE FOR HEALTH AND CARE EXCELLENCE - NICE. Antenatal and postnatal mental health: clinical management and service guidance. London, 2014.

NEOVITA STUDY GROUP. Timing of initiation, patterns of breastfeeding, and infant survival: prospective analysis of pooled data from three randomised trials. The Lancet. Global Health, London, v. 4, n. 4, p. e266-275, Apr. 2016.

PACAGNELLA, R. C. et al. The role of delays in severe maternal morbidity and mortality: expanding the conceptual framework. Reproductive Health Matters, London, v. 20, n. 39, p. 155-163, June 2012.

PACE, R. M. et al. COVID-19 and human milk: SARS-CoV-2, antibodies, and neutralizing capacity. MedRxiv, [s. I.], 2020. Disponível em: https://www.ncbi. nlm.nih.gov/pmc/articles/PMC7523143/. Acesso em: 1 out. 2020.

PANTELIS, C. et al. Neurological, neuropsychiatric and neurodevelopmental complications of COVID-19. Australian \& New Zealand Journal of Psychiatry, [s. I.], p. $0004867420961472,2020$.

PARKER, L. A. et al. Association of Timing of Initiation of Breastmilk Expression on Milk Volume and Timing of Lactogenesis Stage II Among Mothers of Very LowBirth-Weight Infants. Breastfeeding Medicine, New Rochelle, v. 10, n. 2, p. 84-91, Mar. 2015.

POLLARA, J. et al. Association of HIV-1 Envelope-Specific Breast Milk IgA Responses with Reduced Risk of Postnatal Mother-to-Child Transmission of HIV-1. Journal of Virology, Washington, v. 89, n. 19, p. 9952-9961, out. 2015.

PRABHU, M. et al. Pregnancy and postpartum outcomes in a universally tested population for SARS-CoV-2 in New York City: a prospective cohort study. BJOG, Oxford, v. 127, n. 12, p. 1548-155, 2020. 
QADRI, F.; MARIONA, F. Pregnancy affected by SARS-CoV-2 infection: a flash report from Michigan. The Journal of Maternal-Fetal \& Neonatal Medicine, London, p. 1-3, 2020. Disponível em: https://www.tandfonline.com/doi/full/10.1080/14767058.202 0.1765334. Acesso em: 14 jul. 2020.

PATANÈ, L. et al. Vertical transmission of COVID-19: SARS-CoV-2 RNA on the fetal side of the placenta in pregnancies with COVID-19 positive mothers and neonates at birth. American Journal of Obstetrics \& Gynecology MFM, Switzerland, v. 2, n. 3, p. 100145, 2020. Disponível em: https://linkinghub.elsevier.com/retrieve/pii/ S2589933320300896. Acesso em: 6 jun. 2020.

POON, L. C. et al. Global interim guidance on coronavirus disease 2019 (COVID-19) during pregnancy and puerperium from FIGO and allied partners: Information for healthcare professionals. International Journal of Gynecology \& Obstetrics, v. 149, n. 3, p. 273-286, 2020a.

POON, L. C. et al. ISUOG Interim Guidance on 2019 novel coronavirus infection during pregnancy and puerperium: information for healthcare professionals. Ultrasound in Obstetrics \& Gynecology, Chichester, v. 55, n. 5, p. 700-708, 2020 b.

RASMUSSEN, S. A.; JAMIESON, D. J. Coronavirus Disease 2019 (COVID-19) and Pregnancy: Responding to a Rapidly Evolving Situation. Obstetrics \& Gynecology, Hagerstown, v. 135, n. 5, p. 999-1002, May 2020.

REDE MÉDICA PELO DIREITO DE DECIDIR. Nota Oficial: pela manutenção dos programas de planejamento reprodutivo frente a pandemia da COVID-19, 9 abr. 2020. Disponível em: https://assets-institucional-ipg.sfo2. cdn.digitaloceanspaces.com/2020/04/RedeMedicapeloDireitodeDecidir_ NotaPelaManutencaoProgramasPlanejamentoReprodutivo.pdf.

Acesso em: 18 maio 2020.

RIDGWAY, J. P. et al. HIV Care Continuum and COVID-19 Outcomes Among People Living with HIV During the COVID-19 Pandemic, Chicago, IL. AIDS and Behavior, New York, May 2020.

RILEY, T. et al. Estimates of the Potential Impact of the COVID-19 Pandemic on Sexual and Reproductive HealthIn Low- and Middle-Income Countries. International Perspectives on Sexual and Reproductive Health, New York, v. 46, p. 73-76, 2020. 
ROBERTON, T. et al. Early estimates of the indirect effects of the COVID-19 pandemic on maternal and child mortality in low-income and middle-income countries: a modelling study. The Lancet Global Health, London, v. 8, n. 7, p. e901-e908, 2020. Disponível em: https://linkinghub.elsevier.com/retrieve/pii/ S2214109X20302291. Acesso em: 6 jun. 2020.

ROBERTSON, C. A. et al. SARS and Pregnancy: A Case Report. Emerging Infectious Diseases, Atlanta, v. 10, n. 2, p. 345-348, feb. 2004.

ROLLINS, N. C. et al. Why invest, and what it will take to improve breastfeeding practices? Lancet, London, v. 387, n. 10017, p. 491-504, 2016.

SANTOS, D. de D. S. et al. Disproportionate impact of COVID-19 among pregnant and postpartum Black Women in Brazil through structural racism lens. Clinical Infectious Diseases, Chicago, 2020. Disponível em: https://academic. oup.com/cid/advance-article/doi/10.1093/cid/ciaa1066/5877027. Acesso em: 8 jul. 2020.

SCHWARTZ, D. A. et al. Confirming vertical fetal infection with COVID-19: neonatal and pathology criteria for early onset and transplacental transmission of SARS-CoV-2 from infected pregnant mothers. Archives of Pathology \& Laboratory Medicine, Northfield, ILL, v. 144, n. 12, p. 1451-1456, 2020.

SCHWARTZ, D. A.; GRAHAM, A. L. Potential Maternal and Infant Outcomes from Coronavirus 2019-nCoV (SARS-CoV-2) Infecting Pregnant Women: Lessons from SARS, MERS, and Other Human Coronavirus Infections. Viruses, Basel, v. 12, n. 2, p. 194, 2020. Disponível em: https://www.mdpi.com/1999-4915/12/2/194. Acesso em: 18 maio 2020.

SENTILHES, L. et al. COVID-19 in pregnancy was associated with maternal morbidity and preterm birth. American Journal of Obstetrics and Gynecology, New York, v. 223, n. 6, 2020. Disponível em: https://linkinghub.elsevier.com/ retrieve/pii/S0002937820306396. Acesso em: 14 jul. 2020.

SHANES, E. D. et al. Placental pathology in COVID-19. American Journal of Clinical Pathology, Philadelphia, v. 154, n. 1, p. 23-32, 2020.

SHENKER, N. S. et al. Undermining breastfeeding will not alleviate the COVID-19 pandemic. Lancet, London, v. 396, n. 10257, p. 1064-1065, 2020. 
SILVA, V. R. da; FERREIRA, L. Só $55 \%$ dos hospitais que ofereciam serviço de aborto legal no Brasil seguem atendendo na pandemia. Gênero e Número, [s. I.], 2 June 2020. Disponível em: http://www.generonumero.media/so-55-doshospitais-que-ofereciam-servico-de-aborto-legal-no-brasil-seguem-atendendona-pandemia/. Acesso em: 2 jun. 2020.

SMITH, E. R. et al. Delayed Breastfeeding Initiation Is Associated with Infant Morbidity. The Journal of Pediatrics, v. 191, p. 57-62.e2, 1 Dec. 2017.

STUEBE, A. The Risks of Not Breastfeeding for Mothers and Infants. Reviews in Obstetrics and Gynecology, New York, v. 2, n. 4, p. 222-231, 2009.

TAGLAUER, E. et al. Consistent localization of SARS-CoV-2 spike glycoprotein and ACE2 over TMPRSS2 predominance in placental villi of 15 COVID-19 positive maternal-fetal dyads. Placenta, London, v. 100, p. 69-74, 2020.

TAKEMOTO, M. L. S. et al. The tragedy of COVID-19 in Brazil: 124 maternal deaths and counting. International Journal of Gynaecology and Obstetrics, Malden, v. 151, n. 1, p. 154-156, 2020.

TAM, P. C. K. et al. Detectable severe acute respiratory syndrome coronavirus 2 (SARS-CoV-2) in human breast milk of a mildly symptomatic patient with coronavirus disease 2019 (COVID-19). Clinical Infectious Diseases: An Official Publication of the Infectious Diseases Society of America, Chicago, May 2020.

TANNE, J. H. Coronavirus pandemic stirs fight over abortion rights in US. British Medical Journal, London, v. 369, Apr. 2020.

\section{THE AMERICAN COLLEGE OF OBSTETRICIANS AND GYNECOLOGISTS. Novel} Coronavirus 2019 (COVID-19). Washington, 2020. Disponível em: https://www. acog.org/clinical/clinical-guidance/practice-advisory/articles/2020/03/novelcoronavirus-2019. Acesso em: 20 maio 2020.

THORSON, A. E. et al. Ebola virus disease and breastfeeding. The Lancet, London, v. 395. 10223, p. 468, Feb. 2020. DOI: https://doi.org/10.1016/ S0140-6736(19)32967-8. Disponível em: https://www.thelancet.com/pdfs/journals/ lancet/PIIS0140-6736(19)32967-8.pdf. Acesso em: 5 maio 2021.

TODD-GHER, J.; SHAH, P. K. Abortion in the context of COVID-19: a human rights imperative. Sexual and Reproductive Health Matters, London, p. 1-4, Apr. 2020. 
TOLU, L. B.; FEYISSA, G. T. Guidelines and best practice recommendations on contraception and safe abortion care service provision amid COVID-19 pandemic: Scoping review. Research Square, Durham, Apr. 2020. Disponível em: https://www. researchsquare.com/article/rs-25326/v1. Acesso em: 18 maio 2020.

TOWNSEND, J. W. et al. In the response to COVID-19, we can't forget health system commitments to contraception and family planning. International Journal of Gynecology \& Obstetrics, New York, v. 150, n. 3, p. 273-274, Sept. 2020.

TSUTSUMI, H. et al. Immunoglobulin A antibody response to respiratory syncytial virus structural proteins in colostrum and milk. Journal of Clinical Microbiology, Washington, v. 27, n. 9, p. 1949-1951, Sept. 1989.

TUROCY, J. M. et al. The Emotional Impact of the Asrm Guidelines on Fertility Patients During The Covid-19 Pandemic. MedRxiv, [s. I.], Apr. 2020.

Disponível em: http://medrxiv.org/lookup/doi/10.1101/2020.03.29.20046631. Acesso em: 18 maio 2020.

UNA-SUS. OMS - perguntas e respostas sobre COVID-19, gravidez, parto e amamentação. Brasília, DF, 30 mar. 2020. Disponível em: https://www.unasus. gov.br/noticia/oms-perguntas-e-respostas-sobre-covid-19-gravidez-parto-eamamentacao. Acesso em: 23 maio 2020.

UNFPA ASIA PACIFIC REGIONAL OFFICE. Coronavírus (2019-nCOV) guidance document. 6 feb. 2020. Disponível em: https://china.unfpa.org/sites/default/ files/pub-pdf/APRO\%20Coronavirus\%202019-nCoV\%20Guidance\%20Note-\%20 final\%20\%2806\%20Feb\%202020\%29.pdf. Acesso em: 5 ago. 2020.

UNICEF. Coronavirus disease (COVID-19): what parents should know. 2020a. Disponível em: https://www.unicef.org/stories/novel-coronavirus-outbreak-whatparents-should-know. Acesso em: 28 out. 2020a.

UNICEF. Gravidez durante a pandemia da Covid-19. Brasília, DF, 2020b. Disponível em: https://www.unicef.org/brazil/gravidez-durante-pandemia-dacovid-19. Acesso em: 18 maio 2020.

UNICEF. Infant and Young Child Feeding in the Context of COVID-19. 2020c. Disponível em: https://www.unicef.org/documents/infant-and-young-childfeeding-context-covid-19. Acesso em: 29 out. 2020.

UNICEF. Statements on supporting infant feeding during the Covid-19 outbreak. 2020d. Disponível em: https://www.unicef.org.uk/babyfriendly/infant-feedingduring-the-covid-19-outbreak/. Acesso em: 28 out. 2020. 
WANG, D. et al. Clinical Characteristics of 138 Hospitalized Patients With 2019 Novel Coronavirus-Infected Pneumonia in Wuhan, China. JAMA, Chicago, v. 323, n. 11, p. 1061-111069, 2020. Disponível em: https://jamanetwork.com/journals/ jama/fullarticle/2761044. Acesso em: 18 maio 2020.

WANG, S. et al. A Case Report of Neonatal 2019 Coronavirus Disease in China. Clinical Infectious Diseases, Chicago, v. 71, n. 15, p. 853-857, 28 July. 2020.

WORLD HEALTH ORGANIZATION - WHO. Breastfeeding Advice During the COVID-19 Outbreak. 2020b. Disponível em: http://www.emro.who.int/nutrition/ nutrition-infocus/breastfeeding-advice-during-covid-19-outbreak.html. Acesso em: 29 out. 2020.

WORLD HEALTH ORGANIZATION - WHO. Clinical management of severe acute respiratory infection (SARI) when COVID-19 disease is suspected. Interim guidance. Pediatria \& Medycyna Rodzinna, [s. I.], v. 16, n. 1, p. 9-26, May 2020c.

WORLD HEALTH ORGANIZATION - WHO. COVID-19: Operational guidance for maintaining essential health services during an outbreak. 25 Mar. 2020d. Disponível em: https://apps.who.int/iris/handle/10665/331561.

Acesso em: 1 ago. 2020.

WORLD HEALTH ORGANIZATION - WHO. Guideline: Protecting, Promoting and Supporting Breastfeeding in Facilities Providing Maternity and Newborn Services. Geneva: WHO, 2017.

WORLD HEALTH ORGANIZATION - WHO. WHO Recommendations on Postnatal Care of the Mother and Newborn. Geneva: WHO, 2013.

WORLD HEALTH ORGANIZATION - WHO. WHO recommendations on antenatal care for a positive pregnancy experience. Geneva: WHO, 2016. Disponível em: http:// www.who.int/reproductivehealth/publications/maternal_perinatal_health/ancpositive-pregnancy-experience/en/. Acesso em: 29 out. 2020.

WU, Y. et al. Perinatal depressive and anxiety symptoms of pregnant women during the coronavirus disease 2019 outbreak in China. American Journal of Obstetrics and Gynecology, New York, v. 223, n. 2, p. 240.e1-240.e9, Aug. 2020.

YANG, N. et al. Breastfeeding of infants born to mothers with COVID-19: a rapid review. Annals of Translational Medicine, Hong Kong, v. 8, n. 10, p. 618, May 2020.

ZAMANIYAN, M. et al. Preterm delivery, maternal death, and vertical transmission in a pregnant woman with COVID-19 infection. Prenatal Diagnosis, New York, Apr. 2020. 
ZENG, H. et al. Antibodies in Infants Born to Mothers With COVID-19 Pneumonia. JAMA, Chicago, v. 323, n. 18, p. 1848-1849, 2020. Disponível em: https:// jamanetwork.com/journals/jama/fullarticle/2763854. Acesso em: 18 maio 2020.

ZENG, L. et al. Neonatal Early-Onset Infection With SARS-CoV-2 in 33 Neonates Born to Mothers With COVID-19 in Wuhan, China. JAMA Pediatrics, Chicago, v. 174, n. 7, p. 722-725, 2020. Disponível em: https://jamanetwork.com/journals/ jamapediatrics/fullarticle/2763787. Acesso em: 18 maio 2020.

ZELOP, C. M.; BONNEY, E. A. COVID-19 in pregnancy: possible mechanisms not to be discounted. Journal of Maternal-Fetal \& Neonatal Medicine, London, p. 1-4, Aug. 2020.

ZHENG, Q. L.; DUAN, T.; JIN, L. P. Single-cell RNA expression profiling of ACE2 and $\mathrm{AXL}$ in the human maternal-Fetal interface. Reproductive and Developmental Medicine, [s. I.], v. 4, n. 1, p. 7, 2020. Disponível em: http://www.repdevmed.org/text. asp?2020/4/1/7/278679. Acesso em: 7 jul. 2020. 